\title{
A mulher no serviço operacional da Polícia M ilitar de Sergipe: relações de poder e produção de sentido no cotidiano profissional
}

Élida Damasceno Braga ${ }^{1}$

A pesquisa analisou o cotidiano das mulheres policiais que atuam no serviço operacional da Polícia Militar de Sergipe, como é o caso do Batalhão de Choque. As estratégias propostas pelas relações estabelecidas elencam possíveis situações de desrespeito, visto que o modelo de masculinidade é predominante no cotidiano policial. A problemática se deu em torno de compreender como a mulher se caracteriza no âmbito das relações de gênero e poder que ali se estabelecem. Foram realizadas nove entrevistas. A análise permitiu mostrar que a participação das mulheres nesse contexto está envolto por poderes estabelecidos, o não reconhecimento de certas ações em detrimento do modelo de masculinidade, mas também aponta para novas formas de se fazer o policiamento. As mulheres se aliam ao modelo já estabelecido, ampliando-os astuciosamente com outros atributos, utilizando-os como táticas para superar as dificuldades que enfrentam no exercício de sua função.

Palavras-chave: Polícia, trabalho, gênero, desigualdades, policiamento operacional. 


\section{W oman in operational service of M ilitary Police in Sergipe: power relations and meaning of production in professional routine}

\section{Abstract}

The research analyzed the daily lives of women officers who work in the operational service of the Military Police of Sergipe, such as the Shock Battalion. The strategies proposed by the established relationships we list possible situations of non-compliance, as the model of masculinity is prevalent in everyday police. The issue revolved around understanding how the woman is characterized in the context of gender relations and power that there are established. Nine interviews were conducted. The analysis has shown that the participation of women in this context is surrounded by established powers, the non-recognition of certain actions to the detriment of the model of masculinity, but also points to new ways of doing policing. Women are allied to the model already established, expanding them cunningly with other attributes, using them as tactics to overcome the difficulties they face in the exercise of their function.

Keywords: Police, work, gender, inequality. operational policing

\section{Introdução}

As transformações sociais contemporâneas têm incidência direta na composição da força de trabalho. Mudanças de comportamento, aliadas às novas técnicas que o progresso científico proporciona, tais como controle sobre o corpo e expansão da escolaridade, contribuem para o aumento da presença feminina no espaço público. 
No entanto, há ainda diversas dificuldades enfrentadas por mulheres no tocante ao exercício de suas profissões. Um exemplo é o tratamento ainda limitado nas questões de inserção das mulheres nas Polícias Militares. Tal inserção, geralmente, aponta para os ideais de naturalização do trabalho imposto a elas de acordo com a ótica machista.

Uma das primeiras impressões ao ingressar na Polícia Militar foi de instabilidade, bem ao contrário dos sentimentos que me motivaram a enfrentar um concurso público ${ }^{2}$. De início, a empolgação era total por vencer cada etapa que se seguia ${ }^{3}$. A cada fase vencida gerava-se grande expectativa pela seguinte, porém, não dava conta do que viria a vivenciar já no curso de formação.

A transposição do mundo estritamente privado para o público, perfazendo, por assim dizer, uma característica universal das mulheres com minha trajetória de vida, se deu no ano de 2002 quando ingressei na Polícia Militar do Estado de Sergipe. A mulher, mãe, esposa, dona de casa, muito rapidamente (perderia a noção de si), não saberia mais de quem se tratava e nem porque estava ali, haja vista os alunos do curso de soldados serem apenas números com regras e planos a cumprir. Contudo, o desconhecido logo se desfez e, então, meu despertar pelos assuntos que envolvem as mulheres na Polícia Militar começou a aparecer.

Logo que conclui o Curso de Formação de Soldados (CFSd) e fui trabalhar na guarda do Centro de Formação e Aperfeiçoamento de Praças (CFAP) passei, então, a me deparar com as divergências que envolvem o trabalho entre homens e mulheres no universo da instituição militar. Podia observar um tratamento ora extremamente cuidadoso por parte dos homens, ora chegando 
ao puro desprezo. Por vezes era como se não existíssemos, ou melhor, que fosse melhor que ali não estivéssemos. Desenvolver um bom trabalho, bons relacionamentos interpessoais, me colocar numa posição de contribuição, de acréscimo, seria, portanto, o grande desafio a partir de então. Para tanto, a consciência do que era exigido, do que é ser policial militar, para o que eu fui chamada a fazer, o aprendizado diário, foi se consolidando gradativamente. Tudo isso já seria muito se não fosse o fato de estar num ambiente bastante propicio aos homens e pouco adaptado às mulheres, tornando esse período inicial ainda mais complexo.

Observava tudo a minha volta, o tratamento dispensado, as condutas, certos tipos de rotulação, algo comum no ambiente militar. Entretanto, quando a referencia eram as mulheres, os rótulos amplamente se destacavam. As orientações, as observações de comportamentos ao meu redor fizeram com que eu percebesse uma espécie de padrão a ser alcançado através de gestos, de condutas. Assim, aprendi a tratar todos bem, contudo, mantinha certa distância. Aprendi que isso é muito salutar quando se está inserido no mundo masculinizado, cheio de conversas específicas, jeitos de falar e aproximações do tipo que, quando você mantém certa distância, sem precisar destratar, propicia respeito e consideração mútuos.

No CFAP, trabalhei durante cinco anos. Os quatro primeiros foram na Guarda do Quartel, depois um ano na Divisão de Ensino (DE). Ali, concorríamos, além do serviço ordinário, também às escalas extras tipo forró-caju, pré-caju, campos de futebol, entre outros. De lá recebi um convite para ir trabalhar no BPChq em 2007. Chegara, enfim, a hora da atividade fim propriamente dita, ou seja, o combate nas ruas, além de todas as especificidades que o serviço no Batalhão de Choque requer.

Era um terreno totalmente desconhecido para mim. As boas vindas em algumas unidades especializadas da polícia, a exemplo do BPChq, mantêm certos rituais. Por exemplo, todos que 
chegam ao batalhão têm uma espécie de batismo de boas vindas, e, neste caso, não existe acepção de gênero, de hierarquia, todos, sem exceção passam por isso. Comigo não foi diferente, ao chegar já comecei a ser interpelada sobre quando iria pagar a famosa pizza para o $\mathrm{GP}^{4}$ de serviço. Depois desse período, no entanto, é como se você já fizesse parte do contexto e acabam-se todas as brincadeiras e chacotas em torno do novato. Tive oportunidade de observar o quanto a manutenção dessa tradição do pagamento pizza é importante para os componentes do batalhão quando houve uma mudança no comendo da unidade e o então subcomandante decretou o término do pagamento da pizza aos recém-chegados. Aquilo foi uma espécie de afronta, deixando a grande maioria insatisfeita com tal determinação. Eles ficaram indignados, dizendo que era uma tradição antiga do batalhão e não poderia acabar por uma simples determinação. Pude perceber através daqueles discursos o quanto havia ali de importância, de identificador com a idealização de se estar em um Batalhão de Choque. 0 que parecia uma brincadeira sem graça, na verdade era ponto de afirmação para se iniciar o convívio diário. A tradição foi, portanto, restabelecida no comando seguinte, seguindo-se, assim, a rotina da unidade.

Não demorou muito para que me adaptasse à nova rotina. Gostava de estar ali. Gostava da rua, da hora que diziam: "temos que ir!" Quando a velocidade aumentava e a sirene nos alertava de que algo, em algum lugar estava acontecendo e precisava de nós para resolver o assunto. Íamos ao encontro do inesperado. Só se sabia a hora de ir, voltar era sempre uma incógnita. Isso me fascina até hoje no policiamento operacional, pois não temos o controle do tempo, do horário pré-estabelecido como é no serviço burocrático. É comum nas unidades operacionais estarmos em plena atividade, executando serviços burocráticos e, no minuto seguinte, precisarmos sair para o atendimento de ocorrên- 
cias do tipo fuga em presídios, centro de menores infratores, fugas em delegacias, entre outros. E como o Batalhão de Choque abrange todo o interior do estado de Sergipe, as viagens inesperadas acabam virando rotina. É um trabalho árduo que requer disposição, pois não se sabe o que vem pela frente. A evolução de determinadas ocorrências policiais duram tempo demasiado até o seu efetivo controle, podendo os componentes de uma guarnição chegar ao extremo cansaço físico e mental.

No entanto, é nesses trabalhos extremos, pouco rotineiros, onde se abrem oportunidades para desenvolver boas relações. 0 trabalho em grupo, saber que ali o bom desempenho da equipe é fundamental para o bom desfecho do problema, faz com que os atributos de confiança se estabeleçam, além das várias histórias que ficam para serem contadas depois. Sempre procurei trabalhar de igual para igual, ou seja, o que "dava para um dava para todos" 5 . Tipos de comida, horários de trabalho, sem nenhum tipo de predileção. Procurava ouvi-los, mesmo quando o assunto era, tão somente, futebol, carros e mulheres, deixando-os a vontade. Contudo, era comum ouvir vários pedidos de desculpa ao longo do dia pela quantidade de palavrões proferidos. Algumas vezes quando estávamos em patrulhamento pelas ruas de Aracaju, costumava brincar dizendo que precisava passar batom. Isso virava uma tremenda gozação na viatura. Era, na verdade, a minha forma de chamar atenção para o fato de se ter uma mulher na guarnição e ao mesmo tempo estabelecer vínculos de bons tratos diários. Outra coisa que gerou respeito e aproximação foi buscar na experiência dos mais antigos o suporte necessário à minha inexperiência, conquistando, assim, bons relacionamentos que perduram até hoje. Não tinha medo de dizer que não sabia e que queria aprender para não fazer errado quando necessário, já que nem tudo está disposto em manuais.

5 Jargão policial largamente utilizado. 
Uma passagem interessante foi quando tivemos que subir o "morro do avião", no bairro Santa Maria, numa perseguição e fui perguntada pelo sargento comandante da guarnição se queria ficar tomando conta da viatura na parte baixa do morro. Isso seria como assinar um atestado de incompetência, para o que eles comumente chamam de "menos um" na guarnição. Eu respondi: "Não sou motorista sargento, eu vou subir". Peguei a submetralhadora e subi. A vista lá de cima é linda, o cansaço para subir, mais ainda. Entretanto, eu sabia que não havia sido escalada como motorista e sim como patrulheira e conhecia o posicionamento que a função exigia.

Saber, portanto, o que era para fazer dentro de um teatro de operações sempre foi motivo de preocupação. Para tanto, contava o aprendizado de técnicas de abordagem, patrulha, controle de distúrbios civis, bem como a experiência dos colegas e domínio das situações que nos deparavam constantemente, observando cada detalhe de suas atuações me dava o suporte necessário às minhas próprias condutas e desenvolvimento de práticas adequadas. As conversas e a certeza de que eu sabia o que estava fazendo dava segurança a eles também. A postura em serviço era outra coisa que chamava atenção e até hoje chama. Recentemente, no carnaval, fui indagada de como fazia para ter uma postura que intimidava quem estava por perto. A pessoa ainda chegou a dizer que não havia diferença entre o que eu fazia e os demais homens da guarnição. Imediatamente, lembrei-me do modelo que é disseminado ser o da masculinidade. Embora mantenha minhas características femininas na hora do serviço, onde se exige bastante concentração e a observação de tudo e todos que lhe cercam, o fato de permanecer séria remete sempre ao modelo que se estabeleceu de força e masculinidade.

Bem, essas narrativas tem a finalidade de trazê-los o mais próximo da intensidade da vida real, pontuando os sentidos dados ao trabalho desenvolvido, dentre as questões cotidianas apresentadas. 
No mundo do trabalho as transformações são bastante freqüentes. As inovações tecnológicas, o mercado e a concorrência acirrada contribuem para que essa dinâmica atinja os mais diversos setores. A inserção da mulher no mercado de trabalho avança conjuntamente com esse processo, perfazendo um campo vasto para estudos empíricos, no qual o papel da mulher, nas várias esferas de atuação, produz espaço propício para fomentar discussões na área das Ciências Sociais.

Tais transformações ocorrem também no contexto da segurança pública brasileira. Nas últimas três décadas é possível verificar a tentativa de implantar um novo modelo de segurança no país, tendo relevância, segundo Porto (2009), o fato de a violência urbana propagar-se de maneira tal que, a sociedade conclama por ações e decisões por parte do Estado a fim de minimizar a criminalidade e a violência. Outro ponto importante dentro da temática de segurança pública tem sido a articulação do Estado em prol de se mudar a imagem das forças policiais perante a sociedade. De acordo com David Bayley ${ }^{6}$, considerado um dos mais importantes pesquisadores sobre polícias no mundo, as forças policiais precisam ser inteligentes e justas. Inteligentes no sentido de serem capazes de soluções para problemas e locais específicos, criando estratégias e avaliando resultados; e justas como fator determinante para qualidade do trabalho policial, pois através de uma política pautada por valores como honestidade e respeito contribuem para uma maior aproximação com a população.

No Brasil, tais concepções começam a fazer parte da agenda política voltadas para a segurança pública na década de 1980 no sentido de minimizar o afastamento entre polícia e sociedade produzido pelo histórico da ditadura. Paralelo a essas mudanças no cenário das polícias, emerge, internamente, a participa-

$6 \mathrm{Na}$ abertura do II Encontro Anual do Fórum Brasileiro de Segurança Pública realizado em março de 2008. 
ção das mulheres policiais. A presença feminina nas diversas esferas (trabalho, escola, política, ciências) pode ser vista com maior incidência a partir da segunda metade do século XX. No âmbito acadêmico, os estudos de gênero passam a ocupar lugar de destaque nas ciências sociais, mas as discussões sobre o trabalho da mulher nas polícias militares é recente. Elas começam a se tornar visíveis no fim período ditatorial, início da década de 1980, e, desde então, a disputa por esse espaço de trabalho vem se consolidando. Trata-se de um processo lento e gradual, haja vista o modelo de masculinidade amplamente difundido no seio da instituição provocar conflitos. A análise da presença da mulher no processo de trabalho da instituição polícia militar vem, portanto, propor articulações para as questões de gênero suscitadas nesse contexto.

A pesquisa ${ }^{7}$ que originou este artigo buscou compreender em que medida as mulheres atuantes no serviço operacional da Polícia Militar de Sergipe, com foco na capital Aracaju, enfrentam as estratégias propostas pelas relações de força estabelecidas no cotidiano do trabalho. A proposta central consiste em estudar o trabalho realizado por mulheres policiais que estão inseridas nas unidades operacionais da Polícia Militar de Sergipe, como é o caso do Batalhão de Choque, analisando, portanto, as dinâmicas que emergem dessas relações.

Nesse sentido, o problema de partida consiste em compreender como o trabalho da mulher em unidades operacionais, que são lugares construídos de modo masculinizado em seus modelos de ação, ou seja, vistos como redutos masculinos, se caracteriza no âmbito das relações de gênero e poder que ali são estabelecidas. Para tanto, a pesquisa percorreu três dimensões, a saber:

7 Pesquisa de Mestrado intitulada "Mulheres policiais nas unidades operacionais da PMSE:surpresas e mobilidade em meio às práticas ostensivas", sob a orientação do Prof. Dr. Paulo Sergio da Costa Neves, vinculada ao Programa de Pós-Graduação em Sociologia da Universidade Federal deSergipe. 
1. As atividades laborais que são distribuídas entre homens e mulheres;

2. As relações sob a perspectiva de gênero, ou seja, o tratamento dispensado mutuamente;

3. As relações de poder no âmbito da instituição militar a fim de compreender até que ponto interfere no desenvolvimento do trabalho.

O Interesse por essa pesquisa surgiu das minhas inquietações e vivências enquanto integrante da instituição, bem como da curiosidade acerca da incorporação das mulheres policiais em Sergipe e do fato de estar em um ambiente onde o ethos ${ }^{8}$ da masculinidade, ou seja, a concretização da masculinidade, do que é esperado desta, é o paradigma a ser seguido. Esse contraste de estar em um local apenas pensado para homens, onde a base para o bom desempenho profissional é atrelada a atributos tipicamente masculinos, me instigou a compreender e saber mais sobre esse universo empírico que se abriu sobremaneira, às oportunidades de observações. Das primeiras observações surgiu o trabalho de especialização intitulado "Trajetórias identitárias e trabalho feminino nas unidades operacionais da Polícia Militar de Sergipe" desenvolvido junto à Faculdade de Sergipe-FASE/ESTACIO em parceria com Rede Nacional de Altos Estudos em Segurança Pública- RENAESP ${ }^{9}$, em março de 2011.

Diante disso, me debrucei sobre as condições de trabalho de mulheres que atuam em unidades operacionais na cidade de

8 Referente aos valores fundamentais que se relacionam ao que se espera do masculino, traduzido por aquilo que concretiza a masculinidade, por exemplo: força, rigidez, tonicidade, dentre outros.

9 Uma pesquisa bibliográfica de caráter exploratório, orientada pelo Prof. Me. João de Deus Gomes da Silva, visando estudar os aspectos e percepções presentes no cotidiano policial sobre a inserção dos trabalhadores (as) para o exercício de suas funções. 
Aracaju, a saber o Batalhão de Choque ${ }^{10}$, a Companhia de Radiopatrulhamento e o Pelotão de Polícia Ambiental. Por se tratar de ambientes cujos modelos masculinos tradicionais são amplamente difundidos, surgiram, assim, alguns questionamentos em torno de saber se: há situações de discriminação/desrespeito inseridas nessas relações? Quais? Como são elencadas as questões do justo e do injusto no cotidiano laboral? Em que medida o reconhecimento profissional e social tem importância nesse contexto? No entanto, para que essas questões apareçam na pesquisa, não se pôde pensar apenas na abordagem feminina, mas na vivência cotidiana e no olhar do outro sobre si, no qual homens e mulheres desempenham funções específicas para o âmbito policial.

A partir da análise das condições de trabalho das mulheres, foi possível compreender como se dão as relações sociais de gênero ora estabelecidas, bem como as estratégias utilizadas por elas para se firmarem efetivamente nesse espaço, constituindo-se, assim, no objetivo principal da pesquisa.

Nesse sentido, procurei: identificar o processo histórico de inserção das mulheres na Polícia Militar de Sergipe no contexto do mundo do trabalho; apontar as vivências do que se percebe como justo e injusto no cotidiano laboral, bem como as demandas por reconhecimento social sob a perspectiva de gênero; enunciar as competências/habilidades necessárias ao desempenho do trabalho policial entre padrões e normas específicas do cotidiano laboral nas unidades operacionais da Polícia Militar; e analisar os discursos fomentados a partir das relações sociais de gênero que se estabelecem no âmbito do policiamento ostensivo. Desse modo, abriguei estas questões numa mais ampla que problematizava todo o objeto: Quais as táticas utilizadas, pelas mulheres

10 Batalhão de Choque constituiu-se o principal ponto de observações diárias para a pesquisa, mas também participaram policiais femininas de outras unidades que tem como ponto em comum o serviço operacional, como é o caso da CPRp e do PPAmb. 
policiais que atuam no serviço operacional, em meio às estratégias que lhes são impostas, a fim de obter reconhecimento de suas ações, tendo em vista que o modelo de masculinidade é o que se tem como validado no cotidiano das práticas ostensivas.

Vale salientar também que a abordagem referente ao campo da segurança pública brasileira é bastante complexa, envolvendo múltiplos contextos e variações. Assim, a relevância deste trabalho está em trazer à tona o cotidiano dessas (es) profissionais sob o enfoque de gênero, ou seja, as relações de poder que circundam o cotidiano do serviço operacional da PMSE. Dar, portanto, visibilidade a um trabalho ainda pouco exercido por mulheres, com os conflitos inerentes à profissão, bem como as relações desenvolvidas.

Para a realização de uma investigação planejada em etapas ordenadas e de acordo com os objetivos do estudo, os procedimentos adotados foram entrevistas semi-estruturadas e o registro de observações diárias no Batalhão de Choque de Sergipe através das situações que se passam no cotidiano da unidade A metodologia se deu a partir das observações, de nove entrevistas realizadas com mulheres que atuam ou atuaram no policiamento operacional, três entrevistas com homens atuam no Batalhão de Choque e também por pesquisa documental.

O desafio, no entanto, foi o afastamento devido do papel de policial para o de pesquisadora, ora trazendo à memória eventos significativos que foram vivenciados, ora ouvindo conversas informais com os outros policiais. 0 pontapé inicial nas observações se deu de forma bastante tranquila. As indagações foram aparecendo devagar, introduzindo os pontos que interessavam à pesquisa sem maiores problemas por não se tratar de um ator externo ao meio. Desse modo, não houve a estranheza habitual quando se trata de adentrar aos universos de pesquisa. A apreensão dos discursos espontâneos, para, então, analisá-los sob os padrões do que é científico e acadêmico, diferiu da inquietação 
de alguns participantes, durante as entrevistas, bem como daqueles que preferiram não colaborar.

A observação do contexto, em suas minúcias, constitui-se em importante ferramenta de pesquisa antes, durante e depois da coleta de dados. Dessas observações diárias surgiram dados empíricos que serviram de suporte ao trabalho. Delas, das anotações pormenorizadas de todo o processo, amparadas pelo suporte teórico, foi possível dispor de mecanismos para análise, bem como as mudanças significativas que vieram a ocorrer ao longo do processo de pesquisa. Entretanto, a participação do observador nesse processo não é inócua, devendo ser considerada como uma variável, já que não se pode eliminar a influência do observador (BEAUD; WEBER, 2007).

A escolha do universo de pesquisa, o Batalhão de Choque de Sergipe, se deu pelo fato de ser uma unidade operacional caracterizada por condutas específicas e características rígidas muito comuns aos padrões masculinos. A presença das mulheres em unidades operacionais vem compondo mudanças no cotidiano das relações. Tais mudanças aguçam o interesse em saber e compreender estas proporções.

Este artigo traz como recorte a inserção e socialização dessas mulheres, bem como as tensões vivenciadas no cotidiano da profissão policial militar com foco no serviço operacional. Primeiramente, a questão histórica da inserção das mulheres em profissões tipicamente masculinas. Depois, o enfoque recai sobre as tensões vividas entre homens e mulheres que compõem o serviço operacional e as relações de poder vivenciadas nesse cotidiano laboral.

A partir dessa incursão, junto à possibilidade de explorar com mais profundidade o cotidiano do policiamento operacional, com foco no trabalho desenvolvido pelas mulheres, buscou-se as propostas para o trabalho de pesquisa. Este, por sua vez, partiu do pressuposto de que as mulheres que trabalham no policiamen- 
to ostensivo da Polícia Militar de Sergipe têm como estratégia principal para se estabelecer nesse contexto, majoritariamente masculino, a qualificação profissional conjugada à resistência aos estereótipos femininos, a fim de que sejam reconhecidas em suas práticas laborais de modo mais justo. Um segundo pressuposto dá conta de que as práticas sociais são orientadas por relações de poder atreladas aos mecanismos de controle comuns às instituições como a PM, contudo, passíveis de intervenção por parte dos agentes envolvidos de acordo com habilidades específicas.

\section{Aspectos históricos: condicionantes para a inserção das mulheres nas polícias}

As Polícias Militares brasileiras aparecem no contexto da segurança pública como portadoras de poder legítimo, em um corpo disciplinado com vistas ao controle social, normatizando o comportamento público através da consolidação da ordem estabelecida (FOUCAULT, 1987). No entanto, como se trata de um espaço constituído sobre os alicerces da masculinidade, percebe-se, no entanto, a inquietude e os conflitos quando este se abre para a inserção de mulheres no cotidiano do trabalho policial.

Na década de 1950, foi criado em São Paulo, o "Corpo de Policiamento Feminino", sendo o primeiro estado a abrir espaço para a inserção de mulheres nas Polícias Militares do país. As mulheres tinham por atividade fim os cuidados com as minorias, ou seja, crianças, idosos e outras mulheres. A partir da década de 1970, as Polícias Militares brasileiras passaram por um processo de militarização, sendo comandadas por oficiais do Exército Brasileiro, sob um padrão de excessiva burocratização. Nesse período, de acordo com Shactae (2010), a Organização das Nações Unidas instituiu a década da mulher com o intuito de combater as desigualdades de gênero, adotando políticas de defesa dos direitos das mulheres. Com isso, o governo foi influenciado, permitindo, assim, a abertura dos quartéis à participação das mulheres. 
Outro fator de destaque nessa abertura de espaço é que, após o período ditatorial, a presença da mulher começou a ser utilizada com o fim de amenizar a imagem da segurança pública, que se encontrava muito abalada perante a sociedade, tentando a construção de uma polícia mais preventiva através da natureza feminina nas funções de proteção e maternagem. A elas foram atribuídas tarefas de humanização, a fim de reconstruir uma imagem menos repressiva da polícia (MOREIRA; WOLFF, 2009).

As policiais femininas eram, portanto, o cartão de visita da instituição. Havia espaços e afazeres determinados, utilizando a imagem de mulher maternal, feminina, condições estas que lhes foram naturalmente atribuídas ao longo da história, ocorrendo em espaços previamente pensados para veicular a imagem de auxílio e proteção (CALAZANS, 2003).

\section{A socialização inicial: ritmos intensos com fins específicos}

Em uma estrutura hierarquizada como a da Polícia Militar, pode-se observar que a composição e recomposição do espaço dependem de diversos fatores. As ações iniciais dentro da instituição giram em torno de aceitação de normas, fazendo com que se adquiram comportamentos adequados à esfera militar. Para entender o cotidiano de uma instituição policial foi utilizado o aporte teórico dos estudos de Erving Goffman por tratar das interações sociais cotidianas. As instituições militares, que são caracterizadas como instituições totais ${ }^{11}$, nas quais os indivíduos são isolados da sociedade, tendo suas atividades concentradas e normatizadas, foram, então

11 Instituição total definida como um lugar de residência e trabalho no qual um grande número de indivíduos, colocados na mesma situação, separados do mundo exterior por um período relativamente longo, levam juntos uma vida reclusa cujas modalidades são regulamentadas de forma explícita e minuciosa. 
[...] estabelecidas com a intenção de realizar de modo mais adequado alguma tarefa de trabalho, e que se justificam apenas através de tais fundamentos instrumentais: quartéis, navios, escolas internas, campos de trabalho, colônias e grandes mansões do ponto de vista dos que vivem nas moradias dos empregados (GOFFMAN, 1974, p. 17).

Para Goffman (1974), os indivíduos ao ingressarem nessas instituições são separados da sociedade por um período de tempo, estando em igualdade entre si. Tais grupos são submetidos a uma rotina rígida, horários inflexíveis, atividades coletivas, debaixo de autoridade rigorosa, tendo por finalidade mantê-los sob vigilância. Assim, sendo a Polícia Militar um ambiente cercado de simbolismos nas relações de poder tem-se, logo de início, lutas a serem travadas nas relações que ali se desenvolvem, sejam elas hierárquicas ou não.

O aluno (a) ao ingressar na Polícia Militar é submetido ao processo de mortificação do eu apontado por Goffman (1974). No período do Curso de Formação de Soldados (CFSd), a exemplo da turma de $2002^{12}$, era como se quisessem limpar o que eles possuíam de singular e transformar em um padrão específico. É comum ouvir o termo "aluno é bicho ${ }^{13}$ ", referindo-se ao fato de que não devem sequer pensar, não tendo, portanto, identidade própria.

Tal mudança de comportamento é sentida mediante as dificuldades da adaptação. Segundo Goffman (1974), esse ritual de passagem se consolida mediante as barreiras impostas aos novatos para que se destituam de si mesmos, estando assim, inseridos no contexto militar.

12 Concurso público realizado pela Universidade Federal de Sergipe para 200 candidatos, sendo 160 homens e 40 mulheres. A Ata de encerramento do CFSd/2002-2003 da $1^{\text {a }}$ turma foi lavrada no dia 06/03/2003 com um total de 192 concludentes, sendo $37 \mathrm{mu}$ lheres. A Ata da $2^{\underline{a}}$ turma foi lavrada em 14/07/2003 com duas mulheres que voltavam da Licença Maternidade. Assim, concluíram um total de 194 alunos, dentre os quais 39 mulheres. Estes dados foram obtidos junto à Divisão de Ensino do CFAP.

13 Nome dado aos novatos pelos policiais mais antigos. 


\section{H ierarquia/disciplina: pilares que sustentam a ordem e as relações de poder estabelecidas}

A visão e organização do mundo militar são norteadas pelos princípios da hierarquia e disciplina. Isso porque atuam em todas as esferas da vida social militar. 0 poder que é distribuído e normatizado nas instituições militares vai desde a divisão de tarefas e papéis a serem desempenhados às relações de poder com base na obediência às ordens estabelecidas (LISTGARTEN, 2002).

De fato, a hierarquia é ordenada de acordo com postos e graduações ou, quando se trata dos pares ${ }^{14}$, é definida por antiguidade. Aos dois segmentos, os oficiais e as praças cabem, segundo o regulamento vigente, as devidas atribuições. Aos oficiais o exercício de comando, chefia e direção da organização policial e às praças a execução das ordens estabelecidas. Contudo, a hierarquia se mantém em todas as esferas, pois mesmo quando estão em igualdade de patentes prevalece a antiguidade ${ }^{15}$ (ARANHA, 1997).

A disciplina, por sua vez, adestra e molda a massa desorganizada com o objetivo de atender os fins que a instituição requer. Ela traz em si a função de construir corpos submissos e adaptados aos objetivos institucionais, inibindo ações motivadas por interesses individuais (LISTGARTEN, 2002).

Dito de outro modo, a hierarquia e a disciplina são considerados os pilares das organizações militares e têm por finalidade tornar os corpos, que ali se encontram submetidos ao regime, em "corpos dóceis"16. Visto que, "O sucesso do poder disciplinar deve-se

14 Pares no sentido de pertencerem à mesma graduação.

15 Muito comum ouvir entre conversas de policiais uma frase que já se tornou adágio popular:"antiguidade é posto!".

16 Termo cunhado por Michel Foucault. 
sem dúvida, ao uso de instrumentos simples: o olhar hierárquico, a sanção normatizadora e sua combinação num procedimento que lhe é específico, o exame" (FOUCAULT, 1987, p. 153).

As relações de poder também ocultas nas relações de gênero podem ser observadas levando-se em consideração que, quando os seres humanos se reconhecem como homens e mulheres e daí constituem diferentes contextos históricos, culturais e sociais, estão produzindo reagrupamentos e ressignificações na dinâmica dessas relações, ou seja, construindo e reconstruindo esses sujeitos (MEYER, 1996). Para Foucault (1987) os saberes, técnicas e discursos produzidos se misturam com as práticas de poder exercidas sobre os corpos, sendo o poder exercido através do domínio do corpo, sem necessariamente tocá-lo. Muito mais no âmbito da consciência que no físico.

Tais práticas dentro das instituições policiais são constitutivas do que Foucault (1987) chama de adestramento, ou disciplinarização. 0 poder, segundo Foucault (2003), configura-se como um lugar estratégico na sociedade, um tipo particular de relação que influencia e modifica a conduta dos indivíduos. A diferenciação do poder está no fato de que alguns indivíduos podem mais ou menos determinar a conduta de outros, entretanto, não de modo repressivo, usando força física, mas pelos atributos de dominação.

O autor ainda ressalta que, essas construções e reconstruções incidem em resistências e que estão inscritas nas relações de poder de modo pontual. As mesmas assumem posicionamentos variados dentro do contexto, partindo do pressuposto estabelecido pelo autor de que não existe poder sem resistência, haja vista o mesmo poder subordinador é também o elemento pelo qual se pode exercer resistência.

Então, através dessas relações é possível reconhecer as estratégias que homens e mulheres utilizam para conviver e também tomar posições em determinados espaços da sociedade, além da 
possibilidade de se reconfigurar a visão da mulher subordinada ao homem (CAPELE, 2006).

De acordo com Certeau (1994) as estratégias são organizadas tendo como ponto de partida o poder que, na verdade, é o cálculo das relações de força com tipos específicos de saberes para determinar e conquistar um lugar para o sujeito dentro da perspectiva do querer/poder. Essa conquista acontece dada as circunstâncias nas quais os indivíduos podem influenciar e também reinventar aquilo que o influencia, ou seja, criando táticas capazes de subverter aquilo que ora o domina.

\section{M ulheres na atividade policial no Brasil}

As transformações sociais e econômicas impulsionam a participação das mulheres no mundo do trabalho em setores bastante diversificados. Com isso, ampliam-se também os conflitos advindos dessas recentes conquistas. A inserção de mulheres nas forças armadas, por exemplo, permitiu a conquista de espaços até então restritos à presença feminina. Já na Brigada Militar do Rio Grande do Sul, pôde-se observar o perfil e a distribuição entre homens e mulheres na instituição, fixando o olhar nas questões hierárquicas que passam pela dicotomia oficiais/praças, bem como na construção das mulheres em policiais militares. Na Polícia Militar do Paraná, foi criado, em 1979, um documento que definia a participação das mulheres na estrutura policial, de acordo com a finalidade e o emprego das mesmas. Às mulheres cabiam as funções de orientar, informar, proteger, especialmente no trato com outras mulheres, crianças e anciões. Apesar de serem alocadas em situações de policiamento a pé, motorizado, aeroportos, feiras, dentre outros, a elas era proibido o porte de armas. Em Minas Gerais, a Polícia Militar não se preparou para a inserção da mulher. Isso revela a tentativa de se anular as características femininas a fim de se construir apenas a policial militar sob os padrões da masculinidade (LOMBARDI, 2010; CALAZANS, 2003; SHACTAE, 2006; LISTGARTEN, 2002). 
Nesse ínterim, mais de vinte anos se passaram e muitas mudanças nos modos de trabalho ocorreram, necessidades surgiram em diversos pontos do contexto abordado. Todas essas contribuições vistas sob a perspectiva de gênero nos ajudam, no entanto, a pensar e compreender a situação que as mulheres viveram e vivem quando se abordam as questões de policiamento, principalmente o policiamento operacional ${ }^{17}$, ou seja, na atividade fim da Polícia Militar. Segundo Capelle (2006), as mulheres estão debaixo de diferentes visões sociais, em posicionamentos diversos frente à realidade existente, despertando, nas mesmas, uma reflexão para a qual pode haver tanto a transformação como a acomodação ao modelo já existente.

Dessa maneira, apreende-se que as mulheres policiais vêm conquistando, gradativamente, espaços no policiamento operacional ${ }^{18}$, desempenhando funções anteriormente impensáveis para elas.

Considerando essas assertivas, pode-se pensar na inserção das mulheres como um marco significativo para a Instituição policial, na qual se produziu mudanças externas e internas. Dessa maneira, é importante reconhecer que,

[...] as mulheres, mesmo como minorias simbólicas, em uma instituição pautada pelo paradigma da masculinidade, introduziram a lógica da diferença, uma vez que produziram desacomodação, desestabilização e desorganização interna nessas instituições, colocando possibilidades de pensar o medo, o risco do ofício de polícia e um questionamento a respeito da ordem estabelecida (CALAZANS, 2007, p.146).

17Atividade de manutenção da Ordem Pública executada com exclusividade pela Polícia Militar, observando características, princípios e variáveis próprias, visando à tranquilidade pública (Manual Básico de Policiamento Ostensivo, Exército Brasileiro)

18 Neste estudo, entenda-se policiamento ostensivo e policiamento operacional como sinônimo. 
Dentro desse contexto, observa-se que a participação da mulher nas polícias cresce e o policiamento operacional, atividade fim das Polícias Militares, propicia a visibilidade das mesmas.

Foi a partir desse ponto que a pesquisa avançou. Para além de dar apenas visibilidade à trajetória das mulheres policiais, a pesquisa buscou a compreensão dos conflitos gerados nas práticas dos atores envolvidos no cotidiano laboral e como isso afeta o contexto do policiamento operacional. Nesse movimento, observam-se através das estratégias impostas, as táticas desenvolvidas para o estabelecimento e ampliação do número de mulheres no serviço operacional.

\section{A mulher na Polícia M ilitar de Sergipe}

Em Sergipe, o ingresso das mulheres nos quadros da Polícia Militar deu-se no final da década de 1980. Duas são as maneiras de ingressar na Polícia Militar de Sergipe, pelo quadro das praças ou pelo quadro de oficiais.

Os dois quadros de acesso, no entanto, são oferecidos por concursos públicos específicos, ingressando como alunos de soldados ou cadetes, respectivamente. As primeiras mulheres da PMSE foram inseridas no Curso de Formação de Oficiais (CFO), no ano de 1989, em Pernambuco. Em Sergipe ainda não há Curso de Formação de Oficiais. Desde então, elas têm, efetivamente, feito parte de todos os quadros de acesso da corporação. Em 1989, também, foram enviadas mais duas mulheres, desta vez ao Estado do Pará para o Curso de Formação de Sargentos (CFS), passando, posteriormente, o processo de formação a ser executado no CFAP $^{19}$ - Centro de Formação e Aperfeiçoamento de Praças da PMSE, que tem como finalidade a formação, aper- 
feiçoamento, habilitação, e especialização dos quadros das Praças ${ }^{20}$ dando início às turmas do Curso de Formação de Soldados (CFSd). A primeira turma de mulheres data de 1993, na qual foram formadas 41 alunas $^{21}$.

Em 1995 foi criada a Companhia de Polícia Feminina, que teve duração de três anos, sendo desativada em 1998 e seu efetivo distribuído nas demais unidades (COSTA, 2005). Segundo alguns relatos de policiais femininas da época, a companhia foi desativada devido à insatisfação de muitas policiais por serem alocadas apenas em solenidades, nas quais serviam "cafezinhos" ou de entregas de medalhas, o que era uma constante. A restrição do espaço, ou seja, a delimitação do espaço a ser ocupado por elas na corporação gerava tensões. Observe o seguinte relato:

A Companhia feminina por não possuir finalidade específica, como muitas outras, a exemplo do Choque e da CPTran, e acabava sendo chamada para tudo que era solenidade. Eu mesma servi muito cafezinho e entreguei muita medalha, por isso pedimos para sermos distribuídas nas demais companhias para sermos iguais aos outros e fazermos as mesmas coisas (Pfem, 19 anos de serviço).

A Companhia Feminina também realizava policiamento no aeroporto de Aracaju, as revistas no presídio feminino as quintas, sábados e domingos, bem como o serviço de guarda da própria companhia A desativação da mesma partiu da insatisfação entre as mulheres oficiais da época, pelo fato de haver um quadro específico, ou seja, "ser mulher". Na polícia militar há os quadros

20 Segundo Regimento interno da Unidade de Ensino.

21 De acordo com BGO № 225 de 14 de dezembro de 1993 que publicou a Ata de Encerramento do Curso de Formação de Soldados PM/BM - Masc/Fem . 0 curso iniciou com 381 alunos no total. Destes, 26 alunos foram desligados ao longo do curso. Nos desligados havia oito mulheres. Desse modo, o curso que começou com 49 mulheres formou 41. 
de especialistas com funções específicas, como por exemplo, o quadro da banda de música, por haver músicos; o quadro do Hospital da Polícia Militar por haver médicos e enfermeiros, devido as suas especificidades. Entretanto, foi criado o quadro da Companhia de Policiamento Feminino com a especificidade de ser mulher, quando o curso, o salário e todas as previsões na legislação eram iguais para ambos os sexos (SANTOS, 2011).

Além disso, havia ainda outra especificidade. As oficiais não chegariam às posições de comando mais altas da PM, mas, apenas, ao posto de Capitãs. No entanto,

[...] não demorou muito até que a cúpula da Polícia Militar percebesse o equívoco que estava prestes a cometer e corrigiu a tempo. 0 projeto foi revogado no nascedouro, por influência das recém-formadas oficiais que se reuniram e procuraram o comandante geral à época para reivindicarem tratamento igualitário. Utilizando-se dos argumentos que tinham em seu favor, as oficiais conseguiram convencer a cúpula da PMSE a desistir de criar o quadro separado e elas acabaram sendo incorporadas no quadro que já existia (SANTOS, 2011, p. 26).

Assim, em 1998, a Companhia Feminina foi desativada, tendo o efetivo policial distribuído nas diversas unidades existentes na instituição. Atualmente, a PMSE conta com um quantitativo de 320 policiais femininas num universo de 5455 policiais ${ }^{22}$. Isso significa que as mulheres representam, aproximadamente, 6\% do efetivo geral. Nesses pouco mais de vinte anos, podemos perceber que a participação feminina na PM gera inquietações, novas formas de pensar o modo de trabalhar, bem como conflitos que se espalham em diversas vertentes. Embora, se observe em outros estudos que, esta falta de preparo para organizar o 
espaço com a inserção das mulheres, não é uma peculiaridade apenas de Sergipe, é vital que se abra espaço para discussões, trazendo a vida cotidiana das instituições para nos fazer pensar sobre tal contexto.

\section{Batalhão de Policiamento de C hoque: discreta in- serção das mulheres policiais}

Os Batalhões de Polícia de Choque no Brasil foram criados, em sua maioria, para atender a um tipo de policiamento para fins específicos, quando da existência de conflitos e revoluções no país. Possuem nomes diferenciados, obedecendo aos registros e peculiaridades históricas de cada unidade.

O policiamento de choque, nos diversos estados do país, tem em comum suas especificidades. Estas vão do Controle de Distúrbios Civis (CDC), motins e rebeliões em presídios, retomada de locais ou áreas ocupadas, praças desportivas ao policiamento motorizado, ou seja, situações de grave comprometimento da ordem pública segundo as diretrizes observadas.

Em Sergipe, o Pelotão de Polícia de Choque foi criado em 20 de dezembro de 1979 através da lei n. ${ }^{\circ} 2.234$ de 10 de novembro do mesmo ano. Em 2007, passou a ser Batalhão de Choque e, atualmente, tem no seu quadro de efetivo cerca de 170 policiais $^{23}$, dentre os quais $03^{24}$ mulheres.

Algumas demandas do policiamento operacional executadas pelo Batalhão de Choque são: a atuação em praças desportivas, reintegrações de posse ocorridas na capital e interior do estado,

23 Variando de acordo com as publicações diárias do Boletim Geral Ostensivo, no qual são publicadas as entradas e saídas do efetivo.

24 Dados atualizados em 27/05/2014 
ordens de serviços diversas para atender os eventos de médio e grande porte, tais como, carnaval, micaretas, entre outros. Outra destinação para o serviço operacional é a recobertura e saturação em áreas críticas ${ }^{25}$.

Para se configurar historicamente essa inserção no policiamento operacional, buscou-se saber, com ajuda dos relatos de policiais mais antigos, quem foi a primeira policial mulher a trabalhar no Batalhão de Choque em Sergipe.

A primeira mulher a trabalhar no policiamento de Choque foi também uma das primeiras policiais a serem inseridas na PMSE, no curso oferecido para sargentos no Estado do Pará em 1989. No ano de 1999, na graduação de 3ํSargento, após a desativação da Companhia Feminina, foi transferida ${ }^{26}$ para a então Companhia de Choque $^{27}$ sediada no Conjunto João Alves, no município de Nossa Senhora do Socorro. A mesma relata que foi transferida sem o seu conhecimento, ficando dois meses na companhia na função de Sargento de operações ${ }^{28}$. Nesse ínterim,

\begin{abstract}
Executava todos os serviços externos, usando metralhadora além da pistola, com direito às normais escalas extras em estádios de futebol, eventos e o que surgisse. Minha escala era de $12 \times 36$ (o turno numa semana iniciava pela manhã, às $06 \mathrm{~h} 30$ e na semana seguinte era à noite). Após $24 \mathrm{~h}$ de repouso do serviço ordinário já estava [...] pronta para escala extra que sempre surgia (PFem, 23 anos de serviço).
\end{abstract}

25 Isso envolve a apreensão de drogas, arma de fogo, motos e carros roubados, bem como indivíduos em situação de flagrante delito.

26 A transferência se deu no BGO no 058 de 06/04/1999.

27 Essas mudanças de Pelotão para Companhia e depois para Batalhão também são vistas através dos brasões.

28 Função similar ao atual "Supervisor" do Batalhão que é executado por um Tenente. 
Através desta fala, podemos identificar quais os tipos de trabalhos executados em uma unidade operacional. 0 que foi narrado sobre o serviço que se desenvolvia há doze anos, pouco difere do que se executa hoje. A escala de $12 \times 36$ foi alterada para $24 \times 72^{29}$. As instalações atuais do BPChq mantém alojamento feminino em boas condições de uso. A entrevistada ainda contou que na época não havia alojamento feminino, utilizando, portanto, o mesmo espaço que os policiais homens.

\section{0 cotidiano do policiamento operacional: tensões em meio às relações de poder}

O efetivo de mulheres que compõe a Polícia Militar de Sergipe, conforme já fora mencionado, é de cerca de $6 \%$ do geral. Pouco mais de $11 \%$ do efetivo feminino está feminina na Polícia Militar, apesar de pequena, gera inquietações e novas formas de pensar o modo de trabalhar, bem como conflitos que se espalham em diversas vertentes ${ }^{30}$. No cotidiano profissional é importante observar que o espaço das viaturas é ocupado por homens e mulheres policiais que perfazem uma rotina na qual atenção e cuidado com o outro são elementos constantes, a fim de que se estabeleça confiança mútua nas equipes. 0 posicionamento de

29 Trabalha 24 horas e folga 72 horas em escala corrida.

30 Casos como: o das alunas de Sargento que, após vários anos de lutas judiciais obtiveram o direito de serem promovidas por terem sido preteridas em um curso interno em 1997, tendo como amparo legal a lei estadual № 3696/96 que preconiza o mínimo de $10 \%$ para o efetivo feminino nos cursos, concursos, bem como para fins de admissão; e um de bastante repercussão foi o que viveu Cabo PM que no serviço rotineiro de um posto policial, no início de abril de 2011, no bairro Eduardo Gomes em São Cristóvão, a mesma, após dezessete horas de serviço, foi até a sua residência a fim de utilizar o banheiro. Ao retornar ao posto recebeu o comunicado que deveria ligar para um oficial que estava supervisionando a área no dia. Ao telefonar para o superior, esta recebeu a ordem de prisão por abandono de posto, mesmo tendo avisado aos colegas aonde iria. Segundo a Associação de Mulheres da Segurança Pública de Sergipe “O detalhe a importante a ser observado nesse caso é o de que inexiste banheiro ou alojamento feminino no PAC e a casa da policial está localizada a menos de 200 metros do posto". 
cada um, a atenção aos comandos específicos, o perigo iminente de morte ao se realizar o trabalho, revelam circunstâncias extremas nas quais o entrosamento e confiança são cruciais para o desenvolvimento do trabalho.

Fora das ruas, as entrevistadas fazem alusão à questão da falta de estrutura para acomodar as mulheres policiais no serviço operacional, pois ainda existem unidades que não dispõem de alojamento feminino.

[...] a questão da estrutura para as mulheres na polícia não existe. Por exemplo, as mulheres estão na Radiopatrulha há mais de 14 anos e tem um ano apenas que foi criado um alojamento feminino, nem banheiro tinha. Nós usávamos os mesmos banheiros que os homens e as mesmas instalações. Se tivesse uma mulher na guarda, ela ia ter que dormir junto com os homens porque não tinha alojamento, não havia essa capacidade gestora pra perceber que ela tinha que ter os seus aspectos respeitados (PFem, 10 anos de serviço).

Boas condições de trabalho, no entanto, equilibram as tensões existentes nas relações de poder. Todos se igualam quando a questão é o trabalho adequado, com recursos específicos que proporcionam o desenvolvimento das competências e habilidades no cotidiano profissional.

O fragmento a seguir aponta para questões contraditórias que as mulheres enfrentam. Ao mesmo tempo em que querem desenvolver um trabalho igualitário não podem também negar suas especificidades, conforme defendido por Soares (2005). Tais especificidades acabam por contrariar o modelo masculino existente, inibindo as pressões por parte das mulheres. Estas, em sua maioria, adaptam-se à rigidez da disciplina vigente ao invés de resistir ao modelo imposto.

Eu não acredito nessa questão de que fulano é mais capaz que beltrana, eu acredito que eles são capazes de desen- 
volver o mesmo serviço, de desempenhar o mesmo trabalho. Talvez um demore menos que o outro[...] Mas aí são as questões das dificuldades que podem ser observadas entre profissionais do mesmo sexo [....]. É sabido que a mulher tem a compleição física diferente da do homem, mas será que não se pode adequar o trabalho? Adequar as ações até nas questões de equipamentos mesmo, porque nós usamos colete masculino e isso machuca os seios, aperta, comprime, machuca, dói.. Passar 12 horas com um colete masculino... (PFem, 10 anos de serviço).

Essas tensões aparecem com maior força no serviço operacional, pois se em toda a polícia as relações de poder podem ser sentidas através dos pilares da hierarquia e da disciplina, no espaço do serviço operacional elas se acentuam, haja vista nesse espaço não haver nada que tenha sido pensado para a inserção das mulheres. As estratégias utilizadas por quem detém o poder dão conta de dificultar a adaptação das mulheres ao meio. Estas, por sua vez, além de minoria, precisam surpreender e se mover astuciosamente para permanecer no contexto operacional.

Há também questões como aceitação, rejeição, discriminação, negação, acomodação aos padrões existentes, elencadas nos discursos que se seguem:

O maior problema que temos hoje, nós mulheres, é a questão da aceitação perante os outros colegas. Há os que dizem em alto e bom som "eu não trabalho com mulheres" e nós não somos apenas mulheres, somos profissionais de Segurança Pública. Eu não entendo essa incapacidade da maioria dos colegas de compreender as funções desenvolvidas, pois somos pouco mais de trezentos e não temos só trezentos policiais na atividade meio, então [...](PFem, 10 anos de serviço).

As relações de poder que se ocultam nas relações cotidianas entre homens e mulheres apontam para o preconceito e discriminação com relação às mulheres policiais. Com práticas de poder 
exercidos sobre os corpos, sem necessariamente tocá-lo como já fora evidenciado por Foucault (1987) é possível perceber que tais práticas se dão tanto pela questão numérica, haja vista os homens serem maioria como pela vigilância excessiva da conduta, pois as mulheres são observadas em tudo que fazem, sendo sempre motivos de questionamentos e subordinadas ao controle excessivo.

Esse contexto estratégico de dominação se revela em diversas e complexas dimensões. 0 ser mulher, o ser mulher policial militar e o ser mulher policial militar no serviço operacional são diversos fatores que se articulam entre si e contribuem para a consolidação da discriminação nas relações que se formam no cotidiano do serviço operacional.

\begin{abstract}
Na verdade a sociedade é machista, a polícia é machista e há toda uma predominância de um trabalho voltado para a força masculina. Mas, é como eu já falei, tem que haver uma batalha diuturna da mulher pra que ela possa realmente ser vista a priori, ser respeitada como policial, como profissional, como alguém também capaz de desenvolver as mesmas atividades, ou ainda melhor (PFem, 14 anos de serviço).
\end{abstract}

As dificuldades são inúmeras em aceitar e se propor a aceitar a mudança de modelos tão enraizados na sociedade sobre o papel da mulher. Como resultado, todas essas dificuldades vão se transformando em resistências ao sistema. Resistências estas, para as quais Foucault (2003) aponta as diferentes estruturas de poder e como este se constitui em elementos de recusa à sujeição estabelecida.

Dos assuntos abordados, um dos que mais incomoda as mulheres no policiamento ostensivo é quando estas se veem confrontadas pela falta de confiança dos homens no trabalho desempenhado pelas mesmas. Como exemplo, observemos a indignação contida nos discursos que se seguem: 
Eu sou uma espécie de "café com leite", não me colocam num guarnição fixa, fico sempre rodando sem função estabelecida. Deixam-me de lado pelo simples fato de ser mulher. Um homem, por menor experiência que tenha na polícia, ou seja, o mais recruta de todos, tem mais moral do que eu, pois nele confiam e em mim não. É como se eu não existisse aqui! (Pfem, 14 anos de serviço).

O não reconhecimento advindo das injustiças cotidianas gera desprezo social, dificultando a realização de justiça com relação às minorias (NEVES, 2002). Os discursos acima nos dão conta da manutenção do modelo de masculinidade, no qual a capacidade de tomada de decisão, a chefia, os atributos físicos continuam dominando a vida cotidiana de homens e mulheres que trabalham no serviço operacional.

É interessante observar as maneiras de fazer, Certeau (1994), tanto de homens como mulheres no cotidiano operacional. Mesmo diante de escalas de serviço já definidas, é possível perceber os homens querendo dar um "jeitinho" de não ter mulheres na guarnição. Antes, estas precisam provar que podem dar conta do serviço proposto. Contudo, até que isso se torne prática, elas sofrem o constrangimento da preterição, de verem ainda alguns superiores utilizando das patentes para reorientar posições de modo que as mulheres se sintam como "menos um", ou seja, tanta faz estar ali ou não.

Entretanto, podemos perceber avanços quando aparecem discursos que revelam atributos tidos como femininos sendo aliados ao modo de fazer masculino no policiamento operacional. Vejamos:

A mulher veio pra quebrar barreiras. Nós conseguimos chegar numa unidade operacional, mas isso a gente sabe que se demorou a conquistar. Havia muito preconceito em relação à mulher não ter capacidade, nem a força física que o homem tem. Entretanto, o que se requer na maioria das vezes são técnica e astúcia e isso homem ou mulher podem de- 
senvolver. Então a contribuição que nós damos é trabalhar com a mesma competência e com um pouco mais de discernimento e atenção que falta aos homens nos momentos de emoção (Pfem, 06 anos de serviço).

A mulher é muito profissional, persistente naquilo que faz. Tem pessoas que independente de sexo se escoram nas outras, então não da pra dizer por que é mulher, mas porque é profissional ou não. Normalmente a mulher é mais atenciosa, mais observadora. 0 grau de atenção em uma guarnição que tem mulher é bem maior (PM, 14 anos de serviço).

Como se pode observar, as mulheres no policiamento operacional desenvolvem táticas próprias para enfrentar as estratégias que lhes são impostas. Estas, em serviço, são percebidas como mais atenciosas, observadoras, ganhando assim espaço para atuar em um nível mais igualitário. Se o modelo, o padrão a ser seguido é o que exalta as características masculinas de força, rigidez e tomada de decisão rápida, as mulheres que se inserem no serviço operacional inovam quando além de se igualarem nos atributos de aceitação podem ampliar estes com características como maior atenção, sutileza, flexibilidade, sensibilidade, transformando estas em táticas a seu favor.

Assim, a astúcia aparece como mediadora, quando as forças estratégicas que as relações de poder impõem não resta alternativa aos que se encontram na posição de fracos, tornando-se táticas (CERTEAU, 1994). Desse modo, o serviço operacional adquire maior completude em suas ações cotidianas quando conta com a presença de homens e mulheres em uma mesma guarnição.

\section{C onsiderações finais}

No presente artigo propus analisar o cotidiano das mulheres que atuam no serviço operacional da Polícia Militar de Sergipe. Nesse sentido, identifiquei como em diversos estados brasileiros, as mu- 
lheres policiais foram inseridas no período pós-ditatorial, ou seja, meados da década de 1980 com a finalidade de atender às novas propostas para Segurança Pública (SOARES, 2005). A proposta era mudar a imagem de uma polícia repressora por uma "naturalmente" de protetora e maternal (MOREIRA; WOLFF, 2009).

Em virtude dessa inserção, mudanças e conflitos no cotidiano das unidades policiais foram se formando. As mulheres, carregadas de histórias de invisibilidade, chegam a um ambiente propício aos homens, feito para eles, sob seus padrões. Além disso, os pilares da disciplina e hierarquia operando tanto nas relações de gênero como na organização do corpo policial, propriamente dito, de sorte que, a maioria das mulheres optou por se acomodar aos padrões já estabelecidos (CALAZANS, 2003), bem como ao espaço que a elas fora reservado, ou seja, o serviço administrativo, as solenidades e eventos para entregas de medalhas.

Sobre essas relações de gênero pode-se perceber pelos discursos analisados que o tratamento dispensado mutuamente oscila. Por vezes aparecem situações nas quais os homens tendem a proteger as mulheres, alegando a suposta fragilidade das mesmas. Em outros momentos elas são apontadas como preguiçosas pelas mesmas características ressaltadas. Na verdade, modos distintos de manter o trabalho das mulheres nivelado por baixo, ou seja, discursos que se legitimam, estabelecendo as relações de poder que mantêm as mulheres sob o estigma da fragilidade, o qual ressalta a ideologia de inferioridade (GOFFMAN, 1988).

Como resultado, observam-se situações nas quais a discriminação e o desrespeito afloram quando, por exemplo, em algumas falas são elencadas posturas do tipo "não trabalho com mulher". Tais injustiças aparecem no cotidiano das relações, dificultando a aproximação, o reconhecimento do trabalho das mulheres policiais no âmbito da instituição, o qual sofre interferência no seu desenvolvimento cotidiano. 
Assim, as discussões elencadas como pontos de reflexão no decorrer da pesquisa suscitam novas indagações a respeito dessa presença feminina que aumenta, gradativamente, e que se propõe como possibilidade de pensar o outro, bem como a desenvolver novas maneiras de fazer a partir das diferenças.

Outro ponto a ser destacado na análise refere-se às relações que se dão no ambiente do policiamento operacional. São relações imbricadas pelo discurso da aceitação, rejeição, discriminação, negação e acomodação aos padrões existentes. São, na verdade, práticas de poderes exercidos sobre o corpo sem a necessidade do toque como afirma Foucault (1987). Explorando ainda essas práticas de poder, pelos discursos apresentados, é possível apreender sobre adestramento e disciplinarização que são comuns às instituições policiais.

Os discursos das relações sociais apontam para um contexto estratégico de dominação, no qual as mulheres policiais são vistas sob diversos ângulos, sendo excessivamente vigiadas em todas as ações executadas. Isso consolida as discriminações, mas também é propício para gerar resistência, ocasionando o que Foucault (1988) chama de poder negativo e positivo, os quais são capazes de modificar a conduta dos indivíduos nas diversas interações sociais.

Contudo, percebe-se também maneiras de fazer que dão conta de unir modelos já consagrados de masculinidade (força, rigidez) aos atributos ditos femininos (flexibilidade, observação) como formas de inovar e surpreender nas maneiras de fazer (CERTEAU, 1994) o policiamento ostensivo.

Faz-se necessário pensar sobre essas resistências internas, pois ainda que discretas, pelo baixo número de mulheres no policiamento operacional se comparado às que estão empregadas nas áreas administrativas, constituem-se em mudanças significativas no âmbito da PM, pois mostra que as constituições iniciais 
para as quais as mulheres foram elencadas, já não se sustentam mais. Os papéis são diversos, as atividades também e as maneiras de fazer (CERTEAU, 1994) vão se alternando, fazendo com que a estrutura antes proposta apenas para os homens modifique-se, assim como a cultura organizacional.

Como resultado, as mulheres policiais surpreendem ao fortificar a outrora posição de fracas, as quais historicamente foram submetidas. Elas absorvem o modelo existente, transformam o espaço de trabalho com manobras astuciosas, assumindo formas diferentes de fazer aquilo que já está estabelecido como modelo para o policiamento operacional. Com essas manobras o serviço policial ganha em mobilidade, surgindo, assim, novas formas de fazer e de pensar o policiamento ostensivo.

\section{REFERÊN CIAS BIBLIO GRÁFICAS}

ARANHA, Roberto (org.). Constituição do Estado de Sergipe de 1989. Legislação Policial Militar do Estado de Sergipe. Salvador: Garamond, 1997.

BEAUD, Stéphane; WEBER, Florence. Guia para a pesquisa de campo. Petrópolis, RJ: Vozes, 2007.

CALAZANS, M.E. de. Polícia e gênero: mulheres na polícia ostensiva. In: Fórum Brasileiro de Segurança Pública, 2007.

CAPELLE, Mônica C. Alves. 0 trabalho feminino no policiamento operacio-

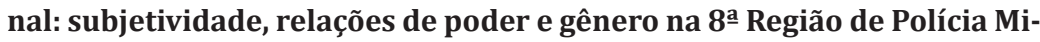
litar de Minas Gerais. Tese (Doutorado) - CEPEAD - Centro de Pós-graduação e Pesquisa em Administração, Belo Horizonte, 2006.

CERTEAU, Michel de. A invenção do cotidiano: 1. Artes de fazer/ Michel de Certeau; tradução de Ephraim Ferreira Alves. - Petrópolis, RJ: Vozes, 1994.

COSTA, Karla Patrícia Barbosa. Processos sociais e educativos na formação do soldado:um olhar sobre a polícia militar de Sergipe. 167f. Dissertação de Mestrado. Núcleo de Pós-Graduação em Educação. São Cristovão/SE: Universidade Federal de Sergipe, 2005. 
FOUCAULT, Michel. Vigiar e punir: nascimento da prisão. Tradução de Lígia M.Pondé Vassallo. Petrópolis: Vozes, 1987.

Michel. História da Sexualidade. A vontade de saber. vol. 1. Rio de Janeiro: Edições Graal, 1988.

, Michel. Estratégia, Poder-Saber. Coleção Ditos e Escritos, v.4. Organização e seleção de textos Manoel Barros da Motta. Rio de Janeiro: Forense Universitária, 2003.

GOFFMAN, Erving. Manicômios, Prisões e Conventos. São Paulo: Perspectiva, 1974.

LISTGARTEN, Silvia Caroline. Diagnóstico identitário da policial feminina na Polícia Militar de Minas Gerais. Monografia (Especialização) do Curso Superior de Administração Pública. Escola de Governo da Fundação João Pinheiro, Belo Horizonte, 2002.

LOMBARDI, Maria Rosa. Profissão: oficial engenheira naval da Marinha de Guerra do Brasil. In: Revista Estudos Feminista. Florianópolis, 2010.

MEYER, D. Do poder ao gênero: uma articulação teórico-analítica. In: LOPES, M. J. M. et al. (Org.). Gênero e saúde. Porto Alegre: Artes Médicas, 1996. p. 41-51.

MINISTÉRIO DO EXÉRCITO. INSPETORIA-GERAL DAS POLÍCIAS MILITARES. Manual Básico de Policiamento Ostensivo.

MINISTÉRIO DO EXÉRCITO. ESTADO-MAIOR DO EXÉRCITO. Manual de Campanha: Ordem Unida. 2 ${ }^{\mathrm{a}}$ Ed., 1980.

MOREIRA, Rosemeri; WOLFF, Cristina Sheibe. A ditadura militar e a face maternal da repressão. In: Dossiê gênero, feminismos e ditadura. Ano X, $2^{\circ}$ semestre 2009. p. 56-65.

NEVES, Paulo Sérgio da Costa. Direitos Humanos e cidadania simbólica no Brasil. In: LYRA, Rubens Pinto (Org). Direitos Humanos: Os Desafios do Século XXI uma abordagem interdisciplinar. Ed. Brasília Jurídica, 2002.

PORTO, Maria Stela Grossi. Realidade, representações sociais e Segurança Pública: uma interpretação. In: MENEZES, Joelina (Org.). Segurança pública: representações sociais e políticas de formamção. São Cristóvão: Editora UFS, 2009.

SANTOS, Amanda Freitas dos. Percepções e perspectivas de mulheres em função de comando na Polícia Militar de Sergipe. São Cristóvão, SE, 2011. 
Monografia (Especialização Violência, Criminalidade e Políticas Públicas) Rede Nacional de Altos Estudos em Segurança Pública, Universidade Federal de Sergipe, 2011.

SCHACTAE, Andréa Mazurok. Vestindo a farda: a identidade da mulher militar na polícia feminina no Paraná em 1977. PR: Capes, 2010.

SOARES, Barbara Musumeci. Mulheres policiais: presença feminina na Polícia Militar do Rio de Janeiro/ Barbara Musumeci Soares, Leonarda Musumeci; com Luciane Patrício e Angélica de Faria Silva. - Rio de Janeiro: Civilização Brasileira, 2005.

Data de Recebimento: 12 de dezembro de 2014

Data de Aprovação: 30 de dezembro de 2014 